\title{
"They say this is a home": the challenge of "home" in residential care settings for old and young
}

\author{
Ulrika Börjesson ${ }^{1,2}$ (D) . Cristina Joy Torgé ${ }^{3}$ (iD
}

Received: 10 June 2020 / Accepted: 25 June 2021 / Published online: 9 August 2021

(c) The Author(s) 2021

\begin{abstract}
In this article, we want to bolster a critical discussion of how the "home" is used in research on residential care, and additionally make sense of young and old residents' feelings of resistance, through the lens of a critical geography of home. We illustrate how the home ideal might be provocative and frustrating for the residents, although previous studies point out that the ideal is used by staff and in policy to reassure residents of a sense of belonging and mastery. Examples from interviews with young unaccompanied boys as well as older residents living in residential care have been used and the analysis resulted in two themes: "Residents' conflicting experiences of space" (shared space, restricted space and regulated space, and "Residents' feelings of homelessness" (transitional space and encroached space). How the residents themselves understand the space that is called their home and why their home can stir ambivalent or negative feelings of isolation, exclusion, and homelessness, is relevant in order to avoid romanticizing home. Residents' understanding of home can be different from the staff, a reminder that home is a much more complex notion than the rosy ideal.
\end{abstract}

Keywords Home $\cdot$ Critical geography $\cdot$ Residential care

\section{Introduction}

Home is a multifaceted concept that not only involves spatial and locational characteristics, but also reflects individual characteristics and values. These different dimensions of home are also used when trying to understand the sense of home in residential care settings. Guided by humanist ideals and as a result of de-institutionalization, the philosophy guiding residential care has moved away from a total institution paradigm to an emphasis on creating spaces that are warm, welcoming and home-like (Nord \& Högström, 2017). Today, the ideal of home permeates many aspects of modern residential care, such as the

Ulrika Börjesson

ulrika.borjesson@ju.se

1 Department of Social Work, School of Health and Welfare, Jönköping University, Jönköping, Sweden

2 Municipality of Jönköping, Social services, Jönköping, Sweden

3 Institute of Gerontology, School of Health and Welfare, Jönköping University, Jönköping, Sweden 
built environment leaning towards small-scale home-like facilities (Eijkelenboom et al., 2017) and normalization of everyday activities that one would do in a domestic setting (Verbeek et al., 2009). Private rooms are now more the norm than an exception in residential care, and residents are encouraged to bring personal possessions to make the space "feel at home" (Lovatt, 2018). Factors such as residents' ability to continue previous activities and to achieve personalization and privacy are also increasingly considered as positive indicators for quality of care in residential care settings (Rijnaard et al., 2016).

Creating and managing home-like spaces in residential care are however complex questions, not least because the sense of home is linked to a sense of identity as well as a sense of connection to the space that may be hard to fully realize in residential care settings. Place attachment or one's bonding to a place has been discussed by Low and Altman (1992), who write that the person-place bond integrates several aspects of experience such as emotional and behavioral aspects, the meanings one gives to a space, collective social bonds, and connections to a place in the past and present. A related concept is Rowles' (1983) concept of insidedness that emphasizes the physical familiarity, social integration, and association of memories to one's home. From a phenomenological perspective, these works underline that people make meaning of and make bonds to home as a spatial, relational and symbolic space. Home in this regard is not limited to the physical site or structure, but fulfills different meanings and roles at various stages of the life course (Low \& Altman, 1992).

The move to a residential care facility, on the other hand, usually follows an uprooting from one's current home, necessitated by circumstances that are beyond the residents' control. Residents often have to adjust to their new surroundings rapidly without having a previous connection to the facility, while also coping with the loss of the old attachments, meanings and roles (Clark, 2014). Feelings of mastery, and belongingness - often associated with the sense of home (Molony, 2010) — are also challenged, as residents must share collective spaces with strangers with whom they may have little in common, and control of one's surroundings may also be limited due to functional- or cognitive decline, social needs and the need for support in everyday life. Residents, however, also actively make meaning of the facility as their new home. Residents will perceive the space differently depending on if it fulfills personal expectations such as privacy, flexibility, or feelings of satisfaction (De Veer \& Kerkstra, 2001). They will also have different experiences about the extent to which the space allows them to pursue personal goals, and if the space is accessible or functional for one's own needs (Kenkmann et al., 2017).

There are previous studies showing that the organization of daily life in residential care facilities still tends to maintain institutional patterns, despite policy ambitions to create home-like spaces that promote autonomy (Peace \& Holland, 2001; Söderqvist, 2016). Residents' preferences, when deviating from established staff routines, may be rendered as disturbances by staff, who postpone or modify residents' wishes (Harnett, 2010). Accordingly, some authors suggest that the ideal to create home-like residential care-although desirable-might be misleading or even a contradiction in terms, especially as belongingness to this "home" is principally grounded on residents' need of care (Fleming, 2017). While the concept of home stirs ideas of informality, kinship and leisure, the nature and function of the space also demands professionalism and public accountability, as well as formal practices and organized ways of living (Peace \& Holland, 2001).

In a previous work (Börjesson \& Söderqvist Forkby, 2020), residents reported that staff often used the home ideal to reassure or calm them. However, the residents' feelings of resistance to this practice were not specifically analyzed. In this article, we want to explore this finding further and at the same time contribute to a critical discussion of residential 
care settings as home. To do this, we combined data from two qualitative studies on residential care in Sweden and conducted a focused secondary analysis. In the data, both authors noted how the young and old residents expressed ambivalent, negative, or resistant feelings regarding the residential care facilities as their home. The aim of our analysis is to make sense of the young and old residents' feelings of resistance through the lens of a critical geography of home, and thus to bolster a critical discussion and of how "home" is used in residential care settings, in policy and research. Critical geography of home: Beyond the home/not home dichotomy

\subsection{Critical geography of home: Beyond the home/not home dichotomy}

The challenges that exist in creating home-like residential care may be partly due to the concept of home itself. The critical geography of home has long called attention to how "home" is used in a romanticized way in research, but it also presents other ways to think about the concept of home. We review some of these discussions below, in particular those raised by Boccagni and Brighenti (2017) and Brickell (2012).

Firstly, the problem of residential care living up to the concept of "home" arises because of tautological definitions. Home has been conceptualized in the social imagination as an inner sanctuary (the realm of the intimate and familiar) that per definition dichotomizes it from spaces "outside" it (the realm of the public and impersonal) (Boccagni \& Brighenti, 2017; Brickell, 2012). Following this definition, it would seem that "home-like institutions" is doomed from the start as paradoxical. Critical geographers of home call attention to this, but also point out how the dichotomy is misleading. It does not consider, for example, the processes of meaning-making and boundary crossing by which unfamiliar places can gradually feel and become more familiar. Researchers such as Mallet (2004) point out that one can also "feel at home" in public spaces, because home is a subjective experience. This idea is also something illustrated by Boccagni and Brighenti (2017) in their concept of "domestication", through which new places, through repeated exposure and association with activities of everyday life, can start to become a part of a familiar realm. In their study's context of migration, they propose that migrants' processes of feeling at home can be understood as a series of passages through zones or thresholds of increasing familiarity, rather than simply being "inside" or "outside" home. Their concept of thresholds loosens up the home/not home dichotomy, and they further introduce the term domesticated place as an area where emotional and physical connections have developed, without necessarily being one's sanctuary or residence. Thus, they propose that instead of defining home through exclusive characteristics, researchers should instead study how people conceive and negotiate the movable borders between material and symbolic spaces of domesticity (Boccagni \& Brighenti, 2017). On a similar note, the related discipline Geography of care has also problematized the dichotomy of public/private in relation to residential care. Often, there is a dual nature of residential care facilities as both a home for residents and a workplace for staff. Similar to the reasoning above, Geographers of care Milligan and Wiles (2010) want to transform the dichotomized idea of public- and private spheres colliding into a concept of a seamless landscape of care where private and public care practices constantly overlap and change. This analogy can be compared to Boccagni and Brighenti's argument that private, communal and public spheres-although each normatively framed by norms, regulations and expectations-are actually permeable and fluid 
and thus can be understood as "interlocked territories" rather than "segmented realms" (Boccagni \& Brighenti, 2017).

Secondly, home has almost unilaterally been defined in the social imagination as positive and rosy. This view has been criticized by geographers of care, who also critique how these preconceived notions have shaped research (Boccagni \& Brighenti, 2017; Brickell, 2012). In research on residential care, we also see this one-sided definition at work, for example though establishing that home-like atmospheres and feeling at home are indications of good care (see Rijnaard et al., 2016). To emphasize this bias, Brickell (2012) draws attention to the fact that home can be a problematic concept. For instance, she points out that home can be a place of negative experiences, domination and exclusion, and not only of harmony and comfort. People can also have mixed feelings regarding their home, challenging the idea of home as merely positive. A few of Brickell's examples, in an article calling for further development of the critical geography of care, are relevant to this current article as they relate to migration of refugees on the one hand, and transition to long-term residential care on the other hand. In her article, she assembled examples from research that shed new light on residents' different understandings of home. One of the ways in which Brickell did this was by highlighting temporality. In an example regarding refugees, the analysis showed that they did not only feel homeless in leaving behind a place, but also by leaving it behind in another time, as they "do not see their homes as being in the present" (Kabachnic et al. 2012 p. 317 in Brickell, 2012). A similar discussion regarding sense of home and impermanence was described among college students who see neither their parental home nor their student apartment as acceptable prospective long-term homes (Kenyon 1999 p. 94, in Brickell, 2012). Both discussions lead to a fascinating interpretation of homelessness, not as a lack of four walls in which to live but as a feeling of something absent in the present. Brickell also raises other aspects of home ambiguity, for example the process of older people's steady divestment from the original home-casser maison ("breaking the house")—-where the status of one's home is gradually but deliberately demoted to a mere house through clearing out possessions and discrediting one's sentimental feelings about the home (Marcoux 2011, in Brickell, 2012). In light of this, it is worth reflecting that the home ideal in residential care thus only represents a very idealized form of what home "ought to be" and in effect—when used in policy day-to-day interactions with staff - can create a normative expectation of what residents "ought to feel" in the lived space. Accordingly, Brickell (2012) argues that it is important to free research of the romanticized and normative notions of home, by giving voice to residents that experience home ambivalence.

In addition to the points raised above, we want to call attention to a third problem in the concept of home when applied to residential care contexts, that has not been particularly touched on in the mentioned discussions. Namely, the binary idea of home/not home also holds within it forms of social relationships and dynamics of social interaction that are taken for granted. A revealing example of this is how research tends to define and study family interactions in residential care as short visiting situations, where significant others are nevertheless "outsiders" (Baumbusch \& Phinney, 2014). Despite the general acceptance of the home ideal in residential care, intimate and familial interactions are framed as out-of-place. Arguably, the nature of residential care as incorporating both public and private attributes, should instead force us to rethink how research dichotomizes intimate and/or casual relationships as strictly belonging to one location or another. As Milligan and Wiles (2010) maintain, residential care facilities should be an excellent case to challenge the conventional separation between the public space as a realm of community and the private space as the realm of intimacy and familiarity. From an architectural perspective, 
the relationships between privacy, connectedness and home are discussed in a recent study by Willems and colleagues on housing projects for refugees (Willems et al., 2020). The authors sought to compare the guiding philosophies about "home" that lay behind the housing constructions, with the residents' own experiences of the houses as a home. Although the authors primarily associated the meaning home to positive social bonds, they also underlined how privacy (individual expression within the home) and connectedness (reaching out to others outside the home) are culturally constructed and overlap. In their participants' process of home-making, they tried to both create familiar social bonds with people outside their home and maintain privacy and integrity through communication of their cultural identity to others, e.g. through the personalization of space around them. Akin to the concept of domestication, home-making thus also extends beyond the borders of one's own dwelling, while privacy and connectedness can be ways of "being at home" that are not limited to the being in one's familiar sphere.

\subsection{Our data: two contexts of residential care}

The data for this article comes from two empirical qualitative studies in Sweden, initiated independently by the two authors in their fields of Social Work and Gerontology. The contexts of the independent studies were residential care units for youth (Hem för vård och boende, hereafter HVBs) on the one hand, and long-term residential care units in old age care (hereafter LTCs) on the other hand. In either study, ambiguity about the home ideal was not originally the main aim. Yet despite studying different residential contexts and having different study designs and aims, the two studies were also similar in that they dealt with residents that, under ordinary circumstances, would not have lived in residential care, and were thus "atypical" residents for the respective settings. In both studies, the situation of unusual residents seemed to underscore the existing challenges in understanding home in residential care. This insight eventually led to the collaboration of the authors on this current article and the decision to re-use the two data sets for secondary analysis focused on understanding the residents' home ambivalence. The contexts and aims of each of the studies are described below.

\subsection{Study 1: Residential care for youth}

The social context framing the first study (conducted 2016-2018 by the first author as primary investigator (PI)) was the immigration of unaccompanied minors to Sweden and the resulting need for housing in one municipality. In 2015, 35000 unaccompanied minors (under 18 years old) were admitted to Sweden as refugees, and 350 unaccompanied minors arrived within a six-month period in the studied municipality. Girls, which represented only one out of 10 among unaccompanied minors, were offered family placement with either distant relatives or foster families, which is a practice followed in other parts of Sweden (Stretmo \& Melander, 2013). The majority of the unaccompanied minors were boys who were offered temporary housing in HVBs.

In ordinary circumstances, HVBs are institutions with a therapeutic aim, for youth who experience troubles in school or cannot live at home due to social, emotional or behavioral difficulties (Severinsson, 2015). However, in this context, HBVs were built to be used as temporary lodging. In spring 2015, there was only one HVB in the studied municipality. In December the same year, ten more residential care units had been arranged quickly to meet the housing needs of the unaccompanied boys. 
The original aim of the study was to explore the unaccompanied boys' experiences of their reception in the studied municipality. For this purpose, nine focus group interviews were conducted with residents at nine of the $11 \mathrm{HVBs}$ in the municipality. Each focus group consisted of 2-9 participants coming from different facilities. XX [Blinded initials of first author], a social work researcher, conducted the focus group interviews together with another researcher and with the help of a translator. The interviews were transcribed verbatim by an assistant, and then analyzed by the researchers. Results have been reported elsewhere (Börjesson \& Söderqvist Forkby, 2020). The theme of home was not actually included in the focus group interview guide, but an observation from the study was that participants expressed negative emotions about the facility being called their "home" by the staff.

\subsection{Study 2: Residential facilities for older adults}

The social context framing the second study (conducted 2016-2019 by the second author as PI) was a new law granting healthy spouses co-residence in LTCs. In Sweden, LTCs are needs-assessed. In other words, in order to be eligible for an apartment in an LTC, a social worker must establish that a person's care needs can no longer be met at one's ordinary home with other services. Medical and residential care are provided in LTCs around the clock, but it is also important to note that apartments in LTCs become the residents' legal home (Socialstyrelsen, 2011). In 2012, to prevent the unwilling separation of couples, a revision of the Social Services Act was enacted, making it possible for residents to bring their spouse as a co-resident. The spouse, in turn, does not need to meet the needs assessment criteria and may be relatively healthy (Swedish Parliament, 2011).

The original aim of the study was to investigate the role of the co-resident spouse in informal caring. Five nursing homes in five Swedish municipalities were selected for the study, based on municipalities that had the most applications for LTC co-residence. Theoretical sampling was also employed for case variation with regard to apartment size, health of spouse and local regulations. The second author, a social gerontologist, conducted one-month long field observations at each site combined with semi-structured interviews with the older couples (11 interviews of 6 couples), semi-structured interviews with the co-habiting spouses (6 interviews) and unstructured interviews with nursing staff (15 interviews). Results are reported elsewhere (Torgé, 2018, 2020). The interview guide did include questions like "do you feel that this place is your home?". However, the couples' experiences of the LTC apartment as a home were not specifically analyzed in these published works.

\subsection{Qualitative secondary analysis}

This current article is the result of the interdisciplinary collaboration of the two authors, where selected data from the abovementioned projects were analyzed together. Ambiguous feelings about the facility as home were raised in different ways by the participants from both studies but were never included in the primary analyses. Thus, in this article the authors conducted a qualitative secondary analysis (QSA) (Tarrant \& Hughes, 2019), using home ambivalence as the shared sensitizing concept for analytical focus. Given the purpose of this current article, only the interviews with the LTC residents (i.e. couples and co-habiting spouses, excluding staff interviews) were included in secondary analysis, while all focus group data from the first study were included. 
A strength of QSA is that it gives researchers the possibility to recontextualize data, allowing new exploration of the previously collected material. According to Irwin and Winterton (2011) qualitative studies often result in a wealth of information, where unexpected, new, or different aspects of data arise that may or may not find their way into the primary project-driven analyses. In secondary analysis, the data can be re-used beyond the original aim of a project, for instance to prioritize a concept that was not the main focus of the original data (Irwin \& Winterton, 2011). This strategy allowed us to revisit textsopen-coded material that had not made its way to the previous analysis — and include these in the current analysis (Assarroudi et al., 2018).

Heaton (2008) differentiates between different types of QSA based on how data is reused. Based on this categorization, we can classify our method as supplementary analysis (where "a more in-depth analysis of an emergent issue or aspect of the data, that was not addressed or was only partially addressed in the primary study, is undertaken") (p. 39), and amplified analysis (where "two or more existing qualitative datasets may be compared or combined for purposes of secondary analysis") (Ibid.) To guide our analysis, we also followed Boccagni and Brighenti's sensitizing question "where does home begin, where does home end?" and applied the concept of thresholds of domesticity to try to make sense of residents' experiences.

There are methodological debates on the status and validity of secondary analysis, specifically when the re-users of data have not been engaged in the original data collection, which may often be the case (Irwin \& Winterton, 2011). In this case, the authors' involvement in the original studies is an advantage to the secondary analysis, as the authors are familiar with the interview data and the context in which they were generated. Proximity to the data arguably allows for reflexivity on the soundness or interpretative validity of what accounts may "mean" for the interview participants, and the theoretical validity of interpreting these accounts from the frame of home and place (Maxwell, 1992). A possible source of bias, however, is that the authors have engaged in the secondary analysis with the aim of exploring and problematizing a specific theme of interest. Although QSA allows for this kind of analysis, we have tried to check bias by discussing our ongoing analyses with each other and checking for trustworthiness vis a vis the contexts of the original studies. The authors discussed their categorizations with others and revised them until a consensus was reached. Preliminary results were also reviewed by colleagues at research seminars.

Another limitation of QSA when exploring a specific issue is that the researchers are limited to the existing data, where the issue explored was not a main object of inquiry. We have tried to look at all instances in the data where residents talked about place, space and belongingness in facility, but of course like other QSA studies, we are limited by our original data. The combination of the two data sets could however also be a strength, for increasing number of incidents found, ability to compare between different contexts, and perhaps most importantly to increase generalizability or relevance of the results.

\subsection{Ethical considerations}

Both studies have been previously approved by the Regional Ethics Committee in Linköping, Sweden (reference numbers blinded) and the data have been archived in the authors' university in accordance with the General Data Protection Regulation (GDPR), where all personal data are removed. In secondary analyses, ethical dilemmas may arise when the data is used for other purposes than what was first intended. As researchers 
involved in the data collection and primary analyses, we sought to re-use the material in a way that reflected actual preliminary findings, to "stay true to the data" by explain participants' experiences through a theoretical frame. The empirical findings can thus be regarded as examples to illustrate and motivate our argument of home as a problematic concept in different residential care contexts.

\section{Results}

Our secondary analysis resulted in two themes relating to residents' understanding of space and home: "Residents' conflicting experiences of space" (in shared space, restricted space, and regulated space), and "Residents' feelings of homelessness" (in transitional space and encroached space).

\subsection{Resident's conflicting experiences of space}

The first theme deals with the residents' conflicting emotions, in the contrast between the ideal of home and actual circumstances. Their experience of the space-as unwillingly shared, restricted, and regulated-made residents feel conflicted about the facilities' status as "their home".

\subsubsection{Shared space}

Personal expression and privacy are often related to the ideal of "home-like" environments. However, in the interviews, the experience of the shared space challenged privacy. Unexpectedly, unwillingly or inadvertently sharing space with others also led the participants to feel isolated, alienated or locked-in, despite sharing space with other people.

For the unaccompanied boys, the residential care facilities in which they lived were existing structures converted as HVB on short notice. The rooms were often relatively spacious and shared by several people as a dormitory room. This meant that the boys shared the rooms with strangers-fellow refugees, but whom they might have little in common in terms of language or identity. One of the boys complained that he shared his room with "three other people I don't really know". Another boy, who identified himself as "the only Christian person [in the HVB], since all the others are Muslim" said that being different made him feel that he was not accepted in the group, and he felt unsafe, especially when arguments developed between the other boys in the facility.

Shared space was likewise a challenge for personal expression and privacy at LTCs, also in a somewhat contradictory experience. One difference from the unaccompanied boy's experience is that the couples share the apartment with people of their choice, which contributed to a sense of home. One resident expressed, pointing to the decorations around the room, that "my wife has had a hand in making this place a home". Another contrast is that in this case, it was the small size of the shared space that contributed to the challenge to privacy. Most apartments were bed-sitting rooms with a private toilet and shower, totaling about 35 to 55 square meters. The apartment's design to suit individuals, rather than couples, limited the couple's freedom for solitude or distance from one's partner. Several participants commented on the challenge of living in a small space, especially if their partner used a wheelchair, or if equipment such as lifts had to be fitted into the apartment. The spouses often provided informal care, but had little opportunity for retreat or respite in this 
small, shared space. Asked if she felt that their 35-square meter apartment was their home, a co-habiting wife said that the little desk in the corner the room provided her only private space, and the communal areas had no room to wind down. She says, "I don't always want to be active with others. I want to be able to sit down and read a book, all alone. I wish that there was a place for stillness here. It would make a difference in how tired I feel."

\subsubsection{Restricted space}

In the HVBs and LTCs, the dormitories and apartments were connected by corridors that also adjoin to communal spaces. The common areas do not belong to any one resident but are designed to welcome all and to encourage natural interactions with others in a semipublic place. Residents, staff and guests move freely in these common areas, which usually consisted of a large living room and a common kitchen, either in an open floor plan or separated by walls. Some facilities also had access to outdoor areas such as a garden, inner courtyard, or porch. In LTCs, it was common for the decoration in these common areas to be reminiscent of a typical Swedish home, with items such as paintings, plants, aquariums, armchairs, pianos, and colorful porcelain in cupboards. In contrast, the HVBs were decorated in a more spartan but functional way. The spaces were not elaborately decorated but allowed activities that would otherwise occur in a home such as relaxing in the sofa or watching TV.

Unlike the situation of sharing private space, it was not the shared nature of communal areas that caused residents' conflicting feelings, as they understood and accepted the presence of others in the communal space. Rather, what was frustrating for residentsin particular for the boys in the HVB - was their lack of access to supposedly common areas. The boys talked about the kitchen as an "off limits" area and believed it unwanted and unfair for the staff to pose restrictions on the space that was also their own. Conflicts with the staff were described when the boys wished to eat at irregular times or opened the refrigerator to snack. Because access to the kitchen was restricted by staff, the boys also felt unable to serve food to visiting guests and thus "to be hospitable in my own home". One boy emphasized that "for us [in our culture] it is important to be hospitable, but we are not allowed to offer anything for friends". The gap between understanding the kitchen as a domestic space at the heart of the home, and the staff-imposed rules limiting access to the kitchen, restricted the boys' possibilities to act like they were "at home". Another challenged the home ideal, saying: "They say that this is our home, but if this was my home I would go into the kitchen and eat whenever I wanted to".

In the LTCs, the residents also hardly entered the common kitchen, but for other reasons. The needs-assessed residents often had multiple functional disabilities that made preparing meals on their own difficult. Instead, the residents paid a monthly fee for meals prepared and served by the staff. Although also often at the center of the facility, the kitchen is also in practice an off-limits space, associated with risks for residents. One major difference from the HVBs is also that the LTC apartments were equipped with a kitchenette, to adhere to building standards of a residential apartment. Although the kitchenettes were seldom used, it afforded the residents the freedom to store their own snacks and entertain guests independently of the staff. In contrast to the boys' experiences the restricted access to the common kitchen was not experienced by the LTC residents as an overstep to their sense of home, as they could fulfill the kitchen's function in their own private apartment. One spouse said, "we could prepare our own meals here if we wanted to, but we thought we'd rather have full board. My wife has a few cakes and goodies here in the pantry, and I 
do the cleaning-up when she's done". It was not uncommon for the LTC residents to refer jokingly to the facility as an "all inclusive-" or "full board-" lodging. Although they said this often with a sense of humor and relief for not needing to cook, it also calls attention to how food preparation is considered by many as part of the everyday activities people associate with home, and how the inability of preparing one's own meals may make the space a little less home-like.

\subsubsection{Regulated space}

Another understanding of space that created home ambivalence for residents was the fact of the space as regulated by others, where residents had little control of the timing of activities around them. This was especially noticeable among the LTC residents. Asked about how their everyday lives looked, they usually replied by reciting or showing a timetable of different daily and weekly activities. Activities such as mealtimes, social activities and help with activities of daily life such as showering, were determined by the clock. Although the schedule was made in dialogue with residents, it was also a function of the staff's work schedule. Mobility in and around the LTC was also determined by the schedule: "They knock at our door and tell us that it's time to come out of the room for lunch or afternoon tea. Or if they have some activities planned, they knock and inform us."

The experience of time and space as structured and occasionally rigid did not feel particularly home-like. For example, when asked to elaborate her feeling of not being really at home, an accompanying wife replied with the time aspect: "One has to keep the time. At one o-clock, we eat. We cannot change that, unlike living at home when you could play it by ear a little bit. You can't do that here." Nevertheless, there was also freedom-if one had good enough reasons- to deviate from the timetable: "If I have an errand and I can't eat here at the specified time, I can tell them to save my meal for me for when I come back, and they heat it up for me when I arrive." The experience of the boys in HVB were similar regarding the timetable. Some boys described how the set times for meals meant that arriving home late from school or training could mean that there was no food left. In some of the facilities, the staff members set rules that the kitchen could not be used certain hours of the day, so the kitchen became off-limits when one arrived "too late".

Space is also regulated by staff as they can alter the layout and the function of a room according to a given activity or goal. In another LTC, the staff proposed, by positioning a dining table in a separate room, that an accompanying wife should eat her meals there with other women instead of at her husband's table, as he needed extensive help from staff with eating. The staff's intention was to provide respite for the spouse. Nevertheless, this illustrates the staff's ability to control the people, items and activities within a given space. Care tasks such as lifting older residents in and out of bed also required a lot of space for ergonomic reasons and the staff's working regulations. These measures are necessary for the safety of the care receiver, but spatially it also limits the spouses' possibilities to decorate freely with furniture such as bookshelves or drawers beside the bed.

\subsection{Residents' feelings of homelessness}

The second theme we found in our material is in line with Brickell's discussion of homelessness as the sense of having abandoned one's home in a previous time and place, and 
where the present "home" also represents an absence. We see this in the residents' understanding of the facility as a transitional space, and the feeling of it being an encroached space and thus having no real place to call home.

\subsubsection{Transitional space}

The residents seemed to accept the HVBs and LTCs were their homes in one sense, but only in the sense of an acceptable dwelling in an inevitable situation, rather than an affective bond. The sense of homelessness within four walls can be sensed in the words of one older resident who said, "Yes, this is our home. We don't really have any other place to call home". One other resident was reluctant to call the apartment his home and described it as being more of a "shelter" that he had little choice but to move to, due to extensive help needs. In Sweden, because LTC residents are usually those with many care needs and multimorbidity, many residents are at the end of life, with many passing away within a year of the transition, sometimes even more rapidly due to extensive needs at admission (Schön, 2016). This could explain this resident's feeling of the apartment as a transitional space and a necessary arrangement until death.

Even for the unaccompanied boys and the accompanying spouses, they also saw the space as transitional, but in a less existential and more practical manner. For them, there was a real risk of being literally homeless. Swedish law requires the unaccompanied boys to move out of the facilities and find their own housing solution upon turning 18 years old. Classified as adult refugees, 18-year-olds are no longer eligible for accommodation in HVBs. During the time of data collection, many of the participants still did not know if they would be granted asylum in Sweden, putting yet another layer of meaning in the impermanence of the place that was supposed to be their home. Like the boys in the HVB, the accompanying spouses' stays in the LTCs were also conditional, and they worried about getting "kicked out" if their partner (the holder of the tenancy contract) passed away. One co-resident spouse described her feeling of insecurity about future homelessness: "When [my partner] dies, maybe I could stay here but maybe they will ask me to move". Another said that she was informed of the local regulations about moving out, underlining the transitory nature of her present home and forcing her to continue paying rent at their old apartment: "[If he dies], I will have to move out within three days. I don't believe they would be so heartless to kick me out, but I would still have to move out pretty fast. I am thinking that I should have a place to go to in case that happens, which is why I still kept our old place."

\subsubsection{Encroached space}

The residents did make an effort to make the space around them more familiar and homelike. A way to do this was to decorate and personalize the space around them. In the HVBs, the boys decorated their room with the few items that they might have had with them from their home countries, and they tried to create a cozy atmosphere, for example through decorations and rugs. In the LTCs, the older residents could bring some of their own furniture, and the apartments were decorated with textiles, photographs, and artifacts from their previous home. These decorations and items from the old home helped to create a sense of home, even in a limited way. As one of the LTC residents said, that "you can't merely transplant a home by transplanting things. The way we live now, we can literally count the things we own." 
The personalization of the space could be a way to increase the feeling of belongingness and ownership, by surrounding oneself with things that affirm one's identity, history and aesthetics. However, these efforts are also sometimes challenged when they feel that the space is encroached on by staff. One of the boys in the HVBs described how he had tried to make his corner of the shared dormitory room his own, but that he felt that the staff did not respect the items that made his space his home. He expressed disappointment when he said, "I have a nice rug in our room and the staff walks in with dirty shoes!" In the LTCs, some residents also felt disappointed when staff members forgot to knock on the door to their apartment before entering. The feeling that others can encroach on the space called home emphasizes the feeling of homelessness within the facility's four walls.

\section{Discussion}

The critical geography of care calls our attention to the normativity of the home ideal, which assumes that home and home-like spaces evoke positive feelings. Through examples from two studies on residential care, we pointed out how the home ideal is applied in less-than-ideal realities, but also how residents can instead have mixed or negative feelings about the "home" they live in. How then, can we use our findings to contribute to a critical discussion of the home ideal?

\subsection{Spatial elements}

The themes we found revolved around the residents' different understandings of space. In different ways, we have seen that the physical characteristics of the HVBs and LTCs contributed to the residents' ambivalence and feeling of homelessness, for instance through shared rooms, small rooms, and limited access to spaces. Although "home" is more than the physical space, this result highlights how spatial elements are an integral part of a sense of place attachment (Low \& Altman, 1992). The appearance and layout of residential care facilities serve as the background and stage for everyday routines, activities, meaning and relationships. While spatial elements can make certain interactions and activities possible, the physicality of space also imposes limits, for instance in the number of people that can fit a room or through the division of space. This understanding that physical space has a form of agency to influence interactions that take place and roles carried out has been described as architectural agency (Nord, 2018). A space becomes a place when it is attached with meanings (Low \& Altman, 1992), and spatial elements—-such as one that separates staff and residents into different locations or encourages contact between residents in collective spaces-impact the subjects' relationships in certain ways. Architecturally, the often-standardized layout of LTCs and the makeshift nature of the HVBs in this study may have also emphasized the residents' ambivalent feelings and the sense of a less-than-ideal "home". Even spatially, the residents live "at the margin of home" (Brickell, 2012).

\subsection{Different boundary-drawing of staff and residents}

One insight from this study has to do with the concept of thresholds of domesticity. Used originally in the context of macro- and meso levels of migration and urban spaces, Boccagni and Brighenti (2017)'s concept is also applicable in our examples, where facilities have private, semi-public, and communal characteristics. For example, it is possible that 
that residents and staff draw from different understandings of the symbolic boundaries of where "home" begins and ends. One specific characteristic of residential care facilities as a site is that practices within it encompass both formal and informal relationships as well as private, semi-public and communal activities (Coolen \& Meesters, 2012; Milligan \& Wiles, 2010). What may be communal for one (such as the example of the facility kitchen) can be semi-public for another, where different behaviors are expected. In the same way, a space that may be semi-public (such as a dormitory room with a rug) can be understood as private with the addition of personal effects, and thus a space that can be encroached. Boccagni and Brighenti's discussion of fluid boundaries between these three spheres thus call to attention how the same space can embrace multiple understandings and that a place that a person calls one's own does need not be limited to the private quarters alone.

That said, there also seems to be an asymmetry in the residents' and staff possibility to draw the symbolic boundaries of space. For instance, staff have access to all locations (including all residents' apartments) while residents have restricted access to certain areas. Within the four walls of the facilities, there is seldom space for residents to be completely private, where the role of "facility resident" can be left behind. In contrast, the staff have the spatial possibility for retreat, as each facility has a staff room, where the role of caregiver can be left for a moment in time.

\subsection{Power structures intersecting spatial structures}

A second insight from our results relates to agency in home-making. In HVBs as well as LTCs, activities and social practices are oftentimes mediated by staff and regulated by a schedule, even if it is done to accommodate residents' wishes. The schedule-oriented day was found by residents to be unlike home. This finding is not surprising given the organization of residential care. It has also been pointed out how the organization of activities tended to frame residents' off-time wishes as exceptions that needed to be motivated (Harnett, 2010). We also observed this in our examples of regulated mealtimes, where exceptions must be reported beforehand and where no meals were served after a certain time of day. Previous studies have likewise discussed the significance of mealtimes, which although aimed at being a pleasurable experience for residents, risk becoming institutionalized and task-oriented (Sidenvall, 1996, 1999).

As Söderqvist (2017) and Söderqvist et al. (2016) show, the regulation of activities within institutional facilities reflects a wider power structure between staff and residents. In addition, we would like to stress that there are also power relations in spatial aspects as well, for instance regarding entry and access and how spaces should be used. Like the example of the couple placed apart at mealtimes, the staff are vested with power to arrange the human and non-human actors through the placement of people together or apart or through how furniture is arranged and re-arranged.

As described previously, the sense of home is complex and includes subjective factors such as residents' ability to achieve their own goals. The sense of home also depends on possibilities for residents to feel that they can "own" the space and encompass it in their sphere of domesticity. It is possible that the staff agency of deciding the time and type of activities in everyday life, limits the sense of being able to domesticate space. 


\subsection{A housing is not a home}

The residents' ambivalent feelings call to mind the adage that a house is not a home. Although we maintain that the home ideal in residential care is important for transforming these places from institutions to facilities that foster the independence of residents, we also showed the need to problematize the idea that merely calling a facility a "home" will mean that residents will see it as one. Conversely, what is also regarded as, or associated with home, may have various meanings.

Coolen and Meesters (2012) invite us to reflect about the concepts "house", "home" and "dwelling" and show how although used interchangeably, the concepts have different meanings. According to them, "home", unlike the other concepts such as "house" or "dwelling", is not fixed to one place or one meaning. It's meaning can shift between referring to 1) the environmental object, or the material structure and physical aspects; 2) the spatial dimensions (such as the house, neighborhood, town, state and country); 3) the temporal facet, which emphasizes home connected to different times in life and the various meanings this might give the home; 4) social relations, referring to family or other groups of significant people; or 5) a process of homemaking and establishing identity in society (Ibid). We see this dynamism in the residents' understandings of home in our studies. For example, the older residents in the LTCs seemed to shift between different geographical places when they talked about home, sometimes referring to their old house or sometimes to their LTC apartment. However, they also suggested that the continuity of intimate connections to the partner is what made the LTC apartment "home" for them.

For the boys accommodated in the HVBs, their longing for a "home" might not even be limited to the four walls of the facility at all, but is extended to the new country, where they wish to seek connections with places and people. As Wernesjö (2020) describes, the public discourse on unaccompanied minors has changed to a more critical tone after 2015. The boys expressed that they wished to assure people they met in public places that their intentions were to work hard and prove deserving of a stay in Sweden. Understanding this longing to belong and to feel at home, not inside, but outside the confines of the facility, can add nuance to why the some of the boys may have rejected the facility's four walls as home. That is, the longing for home extends beyond what can be promised in a HVB, but to "feel at home" in another country.

Through examples from two different studies about residential care for young and old people in Sweden, this article aimed to contribute to a problematized and nuanced discussion of the home ideal in residential care, to give voice to residents' feelings of ambiguity or resistance to the home ideal and make sense of this through the lens of a critical geography of home. By highlighting these experiences, we hope to have contributed to a discussion towards a more complex and critical understanding of "home" in residential care facilities, beyond the home/not home dichotomy.

Author's contribution Each author has collected data independently within the frames of the respective studies. Both authors have had substantial contribution in the manuscript design, new data analysis and manuscript writing.

Funding Open access funding provided by Jönköping University. The study on LTCs in which data for this article is based on has received funding from The Swedish Research Council for Health, Working Life and Welfare (FORTE) Reference No. 2015-00131.

Availability of data and materials Data is stored at Jönköping University in accordance to GDPR law. 


\section{Declarations}

Conflict of interest The authors declare that they have no conflict of interest.

Ethics approval The study design of the study on HVBs was approved by the Regional Ethical Review Board in Linköping (reference number 2016/3178-51). The study design of the study on LTCs was approved by the Regional Ethical Review Board in Linköping (reference number 2015/425-31).

Open Access This article is licensed under a Creative Commons Attribution 4.0 International License, which permits use, sharing, adaptation, distribution and reproduction in any medium or format, as long as you give appropriate credit to the original author(s) and the source, provide a link to the Creative Commons licence, and indicate if changes were made. The images or other third party material in this article are included in the article's Creative Commons licence, unless indicated otherwise in a credit line to the material. If material is not included in the article's Creative Commons licence and your intended use is not permitted by statutory regulation or exceeds the permitted use, you will need to obtain permission directly from the copyright holder. To view a copy of this licence, visit http://creativecommons.org/licenses/by/4.0/.

\section{References}

Assarroudi, A., Heshmati Nabavi, F., Armat, M. R., Ebadi, A., \& Vaismoradi, M. (2018). Directed qualitative content analysis: The description and elaboration of its underpinning methods and data analysis process. Journal of Research in Nursing, 23(1), 42-55.

Baumbusch, J., \& Phinney, A. (2014). Invisible hands: The role of highly involved families in long-term residential care. Journal of Family Nursing, 20(1), 73-97.

Börjesson, U., \& Söderqvist Forkby, A. (2020). The concept of home - unaccompanied youths voices and experiences. European Journal ofSocial Work, 23(3), 475-485.

Boccagni, P., \& Brighenti, A. M. (2017). Immigrants and home in the making: Thresholds of domesticity, commonality and publicness. Springer.

Brickell, K. (2012). 'Mapping'and 'doing'critical geographies of home. Progress in Human Geography, 36(2), 225-244.

Clark, A., Cameron, C., \& Kleipoedszus, S. (2014). Sense of place in children's residential care homes: perceptions of home? Scottish Journal of Residential Child Care, 13(2), 1-13.

Coolen, H., \& Meesters, J. (2012). Editorial special issue: house, home and dwelling. Journal of Housing and the Built Environment, 1(27), 1-10.

De Veer, A. J., \& Kerkstra, A. (2001). Feeling at home in nursing homes. Journal of Advanced Nursing, 35(3), 427-434.

Eijkelenboom, A., Verbeek, H., Felix, E., \& Van Hoof, J. (2017). Architectural factors influencing the sense of home in nursing homes: An operationalization for practice. Frontiers of Architectural Research, $6(2), 111-122$.

Fleming, A., Kydd, A., \& Stewart, S. (2017). Care homes: The developing ideology of a homelike place to live. Maturitas, 99, 92-97.

Harnett, T. (2010). Seeking exemptions from nursing home routines: Residents' everyday influence attempts and institutional order. Journal of Aging Studies, 24(4), 292-301.

Heaton, J. (2008). Secondary analysis of qualitative data: An overview. Historical Social Research/Historische Sozialforschung: 33-45.

Irwin, S., \& Winterton, M. (2011). Debates in qualitative secondary analysis: Critical reflections. Leeds: University of Leeds.

Kenkmann, A., Poland, F., Burns, D., Hyde, P., \& Killett, A. (2017). Negotiating and valuing spaces: The discourse of space and 'home'in care homes. Health \& Place, 43, 8-16.

Lovatt, M. (2018). Becoming at home in residential care for older people: A material culture perspective. Sociology of Health \& Illness, 40(2), 366-378.

Low, S. M., \& Altman, I. (1992). Place attachment (pp. 1-12). Place attachment: Springer.

Mallett, S. (2004). Understanding home: A critical review of the literature. The Sociological Review, 52(1), 62-89.

Maxwell, J. A. (1992). Understanding and validity in qualitative research. Harvard Educational Review, 62(3), 279-300.

Milligan, C., \& Wiles, J. (2010). Landscapes of care. Progress in Human Geography, 34(6), 736-754. 
Molony, S. L. (2010). The meaning of home: A qualitative metasynthesis. Research in Gerontological Nursing, 3(4), 291-307.

Nord, C. (2018). Resident-centred care and architecture of two different types of caring residences: A comparative study. International Journal of Qualitative Studies on Health and Well-Being, 13(1), 1472499.

Nord, C., \& Högström, E. (2017). Caring architecture: Institutions and relational practices. Newcastle Upon Tyne: Cambridge Scholars Publishing.

Parliament, S. (2011). Rätten att Få Åldras Tillsammans: En Fråga om Skälighet, Värdighet och Välbefinnande i Äldreomsorgen [The Right to Age Together: A Question of Reason, Dignity, and a Good Life in Old Age Care]. Prop., 2011(12), 147.

Peace, S., \& Holland, C. (2001). Homely residential care: A contradiction in terms? Journal of Social Policy, 30(3), 393-410.

Rijnaard, M., van Hoof, J., Janssen, B., Verbeek, H., Pocornie, W., Eijkelenboom, A., Beerens, H., Molony, S., \& Wouters, E. (2016). The factors influencing the sense of home in nursing homes: A systematic review from the perspective of residents', Journal of Aging Research, 2016.

Rowles, G. D. (1983). Place and personal identity in old age: Observations from appalachia. Journal of Environmental Psychology, 3(4), 299-313.

Schön, P., Lagergren, M., \& Kåreholt, I. (2016). Rapid decrease in length of stay in institutional care for older people in Sweden between 2006 and 2012: Results from a population-based study. Health \& Social Care in the Community, 24(5), 631-638.

Severinsson, S., Nord, C., \& Reimers, E. (2015). Ambiguous spaces for troubled youth: Home, therapeutic institution or school? Pedagogy, Culture \& Society, 23(2), 245-264.

Sidenvall, B. (1999). Meal procedures in institutions for elderly people: A theoretical interpretation. Journal of Advanced Nursing, 30(2), 319-328.

Sidenvall, B., Fjellström, C., \& Ek, A. C. (1996). Ritualized practices among caregivers at meals in geriatric care. Scandinavian Journal of Caring Sciences, 10(1), 53-61.

Socialstyrelsen. (2011). Bostad $i$ särskilt boende är den enskildes hem Socialstyrelsen.

Stretmo, L., \& Melander, C. (2013). Får jag vara med? Erfarenheter från.

Söderqvist, А. (2017). The (re) construction of home: Unaccompanied children's and youth's transition out of care. Jönköping University.

Söderqvist, ̊., Sjöblom, Y., \& Bülow, P. (2016). Home sweet home? Professionals' understanding of 'home'within residential care for unaccompanied youths in S weden. Child \& Family Social Work, 21(4), 591-599.

Tarrant, A., \& Hughes, K. (2019). Qualitative secondary analysis: Building longitudinal samples to understand men's generational identities in low income contexts. Sociology (Oxford), 53(3), 538-553. https://doi.org/10.1177/0038038518772743

Torgé, C. J. (2018). Whose right to a "Reasonable Level of Living"? Spouses with differing care needs in Swedish nursing homes. Journal of Ageing and Social Change, 8(1), 45-60.

Torgé, C. J. (2020). "Being in-Between": Spouses that cohabit with and provide care for their partners in nursing homes. Journal of Applied Gerontology, 39(4), 377-384.

Verbeek, H., Van Rossum, E., Zwakhalen, S. M., Kempen, G. I., \& Hamers, J. P. (2009). Small, homelike care environments for older people with dementia: A literature review. International Psychogeriatrics, 21(2), 252-264.

Wernesjö, U. (2020). Across the threshold: Negotiations of deservingness among unaccompanied young refugees in Sweden. Journal of Ethnic and Migration Studies, 46(2), 389-404.

Willems, S., De Smet, H., \& Heylighen, A. (2020). Seeking a balance between privacy and connectedness in housing for refugees. Journal of Housing and the Built Environment, 35(1), 45-64.

Publisher's Note Springer Nature remains neutral with regard to jurisdictional claims in published maps and institutional affiliations. 